\title{
Belphégor
}

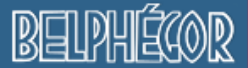

Littérature populaire et culture médiatique

$18-2$ | 2020

Roman Populaire Espagnol - Roman historique, 1900-1950

\section{El enigma de Taxi Key}

Pablo Márquez

\section{(2) OpenEdition}

Journals

Edición electrónica

URL: http://journals.openedition.org/belphegor/3107

DOI: $10.4000 /$ belphegor.3107

ISSN: 1499-7185

Editor

LPCM

Referencia electrónica

Pablo Márquez, «El enigma de Taxi Key», Belphégor [En ligne], 18-2 | 2020, mis en ligne le 11 décembre 2020, consulté le 28 avril 2021. URL : http://journals.openedition.org/belphegor/3107 ; DOI : https:// doi.org/10.4000/belphegor.3107

Este documento fue generado automáticamente el 28 abril 2021.

\section{(c) (i) (9)}

Belphégor est mis à disposition selon les termes de la Licence Creative Commons Attribution - Pas d'Utilisation Commerciale - Pas de Modification 4.0 International. 


\title{
El enigma de Taxi Key
}

\author{
Pablo Márquez
}

1 Analicemos los presupuestos fundamentales de esta colaboración:

\section{Su creador}

2 Luis Gossé De Blain es un andaluz de origen belga. Hijo de un arqueólogo belga y de madre andaluza, de Blain había nacido en Herrerías (Cuevas de Almanzora, Almería) en 1916, aunque en 1920 la familia se trasladó a Barcelona, ciudad donde transcurrió toda su vida, ya que falleció en ella en noviembre de 2001.

3 Fue guionista de una quincena de películas, entre ellas Las tinieblas quedaron atrás (1947), Las hijas del Cid (1962), Todos eran culpables (1962), La boda era a las doce (1964), Detrás del silencio (1972) y La mansión de la niebla (1972). Entre ellas no faltó algún spaghetti western, aunque siempre en colaboración, ya que en estas películas la lista de escritores era casi más larga que la de actores: La muerte llega arrastrándose (1972) y El blanco, el amarillo y el negro (1975).

Desarrolló una importante labor como periodista en diversas publicaciones, como La Gaceta Ilustrada, ¡Hola!, Garbo, Lecturas, Ondas o Tururut y fue durante ocho años redactor jefe de Fotogramas, donde creó el célebre personaje Mr. Belvedere.

5 También intervino en algunas producciones teatrales.

6 Sin embargo, la labor más importante de Luis Gossé De Blain se desarrolla en la radio, concretamente en Radio Barcelona, donde empieza en 1942 y va consolidándose como guionista, hasta que en 1945 crea un concurso que incorpora elementos dramáticos: «Piense y acierte», embrión o prototipo que en 1948 germinaría en «¿Es usted un buen detective?», un programa de media hora de duración que mezclaba la radionovela y el concurso, protagonizada por Taxi Key, un abogado que no encuentra trabajo y cuya sagacidad y dotes de deducción le llevan a actuar de detective.

7 Pronto el programa adoptaría el nombre de su protagonista, y Taxi Key se convertiría en una de las radionovelas españolas más longevas, prolongándose sus emisiones, de media hora de duración, hasta 1962. 
La serie estaba constituida por un relato, una narración de corte policiaco en la cual el sagaz taxista detective descubría al criminal a través de algún error que este había cometido. Los radioyentes que supieran encontrar esas pistas y averiguaran la solución, se llevaban un premio.

\section{La radio de la época}

En 1948, fecha del nacimiento de Taxi Key, la radio era la reina sin competencia en los hogares españoles; no obstante, y aunque nadie podía calcularlo y ni siquiera presentirlo, había nacido quien la llevaría a su ruina: durante una exposición de tecnología en la feria internacional de muestras celebrada en el Palacio de Montjuïc de Barcelona, la casa Philips Ibérica instala una cámara unida por cable a un monitor situado a treinta metros. Enriqueta Teixidó y Enrique Fernández fueron los primeros locutores españoles que aparecieron en pantalla.

Ese mismo año se retransmite al Círculo de Bellas Artes una corrida de toros, emisión que es un fracaso por las deficiencias de imagen y sonido.

11 Las pruebas se suceden, hasta que en 1956 nace oficialmente TVE.

12 Pero en los años 40, y hasta más de dos décadas después, la radio era el medio publicitario por excelencia para todas las grandes marcas comerciales, y esto permitía la emisión en directo de grandes programas, con la participación de los grandes artistas del momento.

Las radionovelas.

14 Esas radionovelas donde un gran equipo de profesionales trabajaba con un derroche de medios impensable hoy en día: un técnico de efectos especiales, capaz de crear la ilusión de sonidos ambientes con los objetos más dispares: el tic-tac de un reloj golpeando el anillo con un bolígrafo, el ulular del viento agitando la hoja de una sierra, el crepitar del fuego arrugando un papel, etc.; técnicos de sonido para evitar ecos, distorsiones de voz, etc.; y sobre todo, ese cuadro de actores de voces atractivas, sugerentes, dramatizando un momento tenso, enfatizando una situación especial, creando imágenes en la imaginación de sus oyentes con el poder de sus voces.

Observen en el cuadro de actores de Taxi Key a Adolfo Marsillach, Ricardo Palmerola, e Isidro Sola, entre otros, en esta fotografía de 1949. 


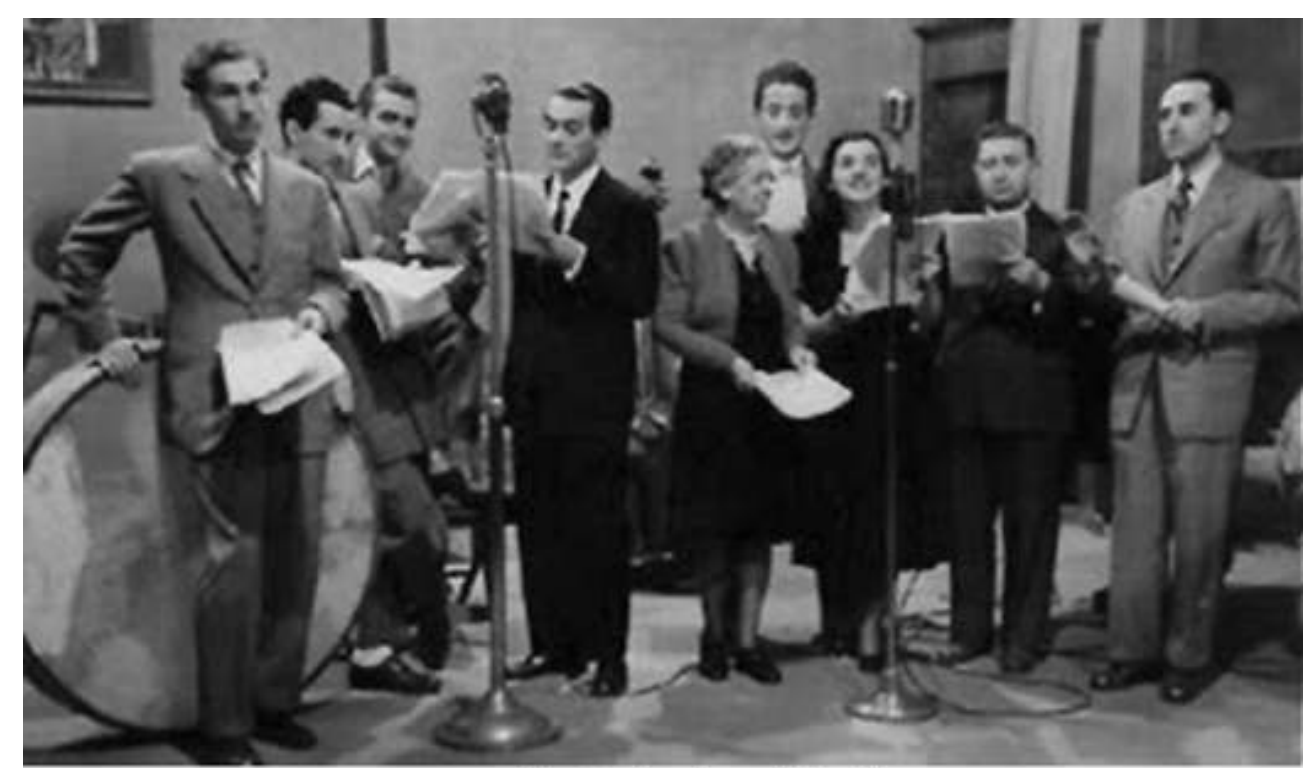

Cuadro de actores de Taxi Key

\section{Taxi Key en la radio} parte más importante de su carrera se desarrolló en la radio y como actor de doblaje. No obstante, su carrera teatral tiene cierta importancia, como El tragaluz, de Antonio Buero Vallejo, o Complejo de Champagne, una comedia de éxito donde intervino durante su representación en Puerto Rico en uno de los principales papeles; y también hizo bastantes películas, algunas de ellas como protagonista.

En 1948 encarna (vocaliza, más bien) a Taxi Key y en el imaginario de todos su voz queda asociada al taxista detective, mientras Amelia Nogués vocaliza a su novia, la periodista Geraldine Brooks. Cuando Amelia marcha a Italia con un contrato, de Blain decide que en vez de cambiar la voz del personaje, es mejor cambiar el personaje entero, y así sustituye a Geraldine Brooks por Nora, otra periodista, a la que casa con Taxi Key y además la hace su secretaria, ya que en su pluriempleo el oficio de detective prevalece sobre el de taxista.

Pero cuando en agosto de 1949 Palmerola se marcha a Cuba, el golpe es tan duro para de Blain, que identifica su voz con el detective, que quiere matar a Taxi Key y abandonar la serie, pues según decía: «difícilmente concibo a Taxi Key a través de un intérprete que no sea Palmerola». tiene una voz magnífica y su capacidad para dar vida sonora al personaje queda demostrada.

Físicamente no tiene la presencia de Palmerola, que resulta bastante más apuesto y apto para hacer de galán en la pantalla.

21

No para aquí la cosa, y un mes más tarde, en septiembre, se marcha Maribel Casals, que daba voz a Nora: a estas alturas, de Blain está ya tan acostumbrado a tanto cambio que se lía los guiones a la cabeza y le da igual todo. Encarna Sánchez (no la de noche, esta es actriz y no periodista) la sustituye. 
La pareja protagonista, Isidro Sola y Encarna Sánchez, funciona perfectamente y la audiencia no abandona la serie, por el contrario es un éxito.

\section{Ricardo Palmerola, la imagen de Taxi Key}

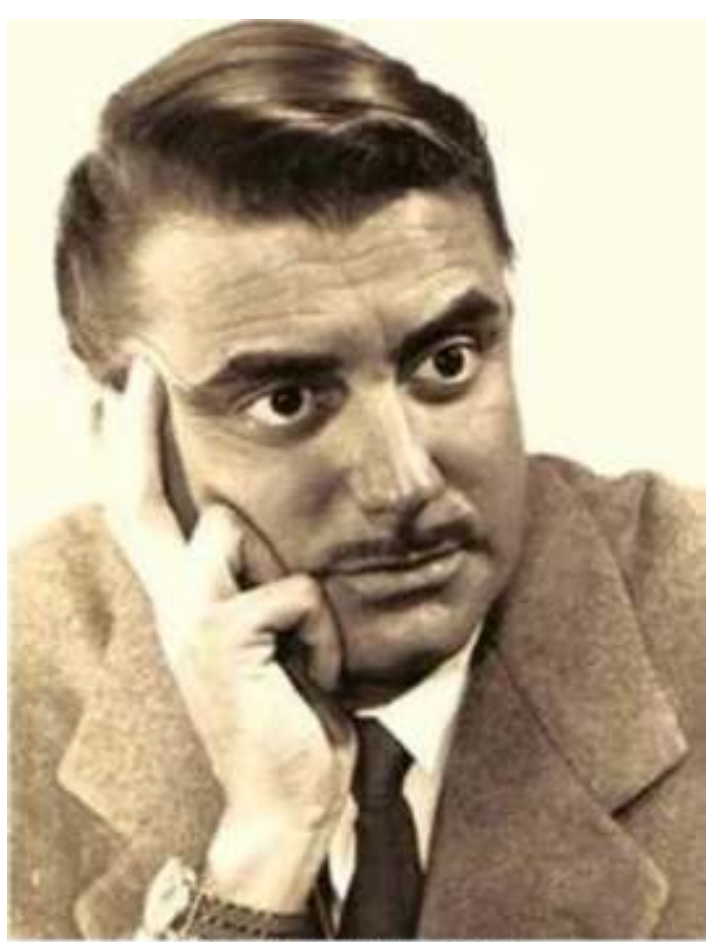

\section{Ricardo Palmerola}

Como he dicho, inicialmente la voz de Ricardo Palmerola queda vinculada al personaje de Taxi Key; posteriormente -y de ello escribiré más adelante- a través del cine también queda asociada su imagen al detective: si pienso en Taxi Key, viene a mi memoria la efigie con bigote de Palmerola.

Palmerola era muy popular en Barcelona. Cuando marchó a Cuba en 1949, Adolfo Marsillach decía en su libro de memorias que, «el puerto de Barcelona se quedó pequeño para decir adiós al ídolo del momento...».

De Cuba fue a Puerto Rico en 1951, donde contrajo matrimonio con Yolanda Villavicencio y fue su hogar durante muchos años.

En Puerto Rico fue actor y director de doblaje, interviniendo en el doblaje de numerosas películas y series de televisión, como Bonanza o Perry Mason.

Como actor de cine participó en numerosos filmes. Debutó con un pequeño papel en Despertó su corazón (1949), una comedia intranscendente sobre un despiadado directivo encarnado por José Nieto.

Alto y apuesto, aunque algo pasado de peso, dio el físico de galán en comedias como $\mathrm{Tu}$ marido nos engaña. 


\section{Taxi Key en el cine}

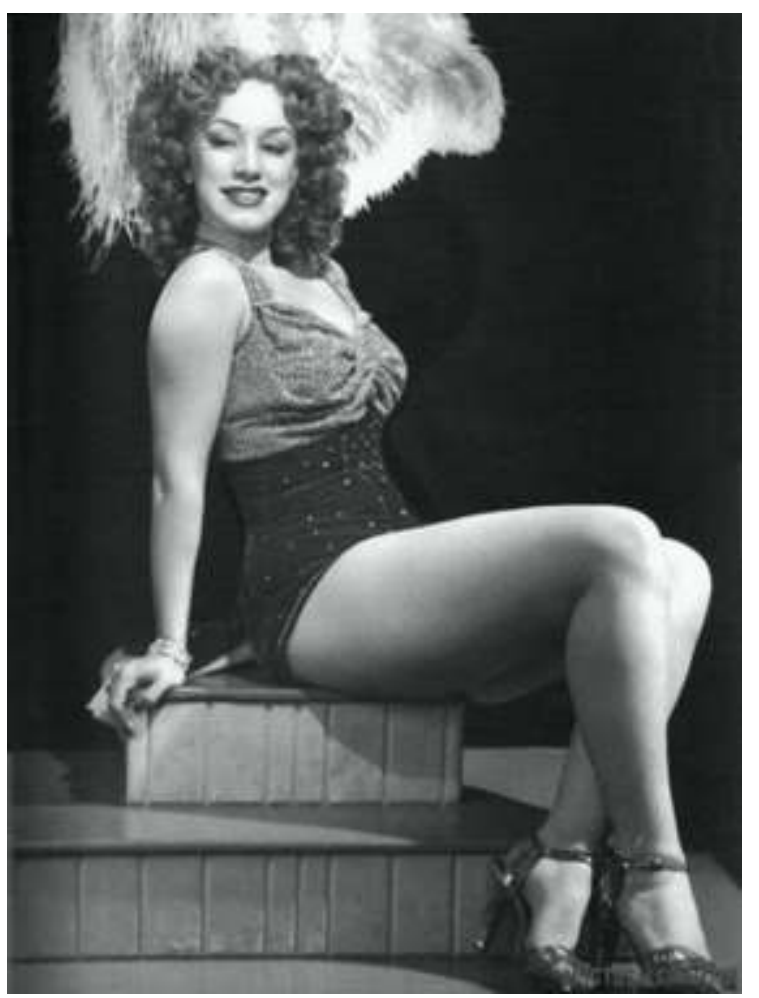

En 1959 salta Taxi Key a la pantalla. Las aventuras de Taxi Key englobaba tres cortometrajes: La mano cortada, La casa del lago y Sombras de un sueño, dirigidos por Alberto G. Nicolau, Arturo Buendía y Juan Fortuny. Los guiones de Luis Gosse de Blain, por supuesto.

En principio estuvieron destinadas a la televisión, de ahí su corta duración.

La pareja protagonista es Ricardo Palmerola e Inés Alma, una modelo descubierta por Juan Fortuny que debutaba en el cine en ese film en el papel de la secretaria de Taxi Key, Nora. La carrera cinematográfica de Inés Alma fue apenas un destello, ya que tan solo intervino en tres películas: La aventuras de Taxi Key (1959), Palmer ha muerto (1961) y Mañana será otro día (1967).

Palmer ha muerto fue una especie de continuación de Taxi Key, tanto por su argumento que nos lo recordaba (un abogado envuelto en una enrevesada trama criminal), como por todo el equipo del film, desde la pareja protagonista (Ricardo Palmerola e Inés Alma), hasta el director, Juan Fortuny, que asumió también las labores de producción y de dirección de fotografía; el guion, también de Luis G. De Blain, y dos directores de episodios de Taxi Key, Alberto G. Nicolau y Arturo Buendía, asumieron las labores del montaje y de la ayudantía de dirección. Quizá el mayor aliciente con que contó la película fue la presencia de la exuberante Rosita Fornés, cantante y actriz cubana nacida un 11 de febrero de 1923, cuyos fabulosos muslos bien se merecen al menos un par de fotos. 


\section{Taxi Key en la historieta} menos que preguntarse cuáles podrían ser las razones por las cuales este personaje no gozó de una mayor popularidad. En este ejercicio de especulación empezaré por el cine, por parecerme que el fracaso en este medio es el más fácil de deducir.

\section{El cine}

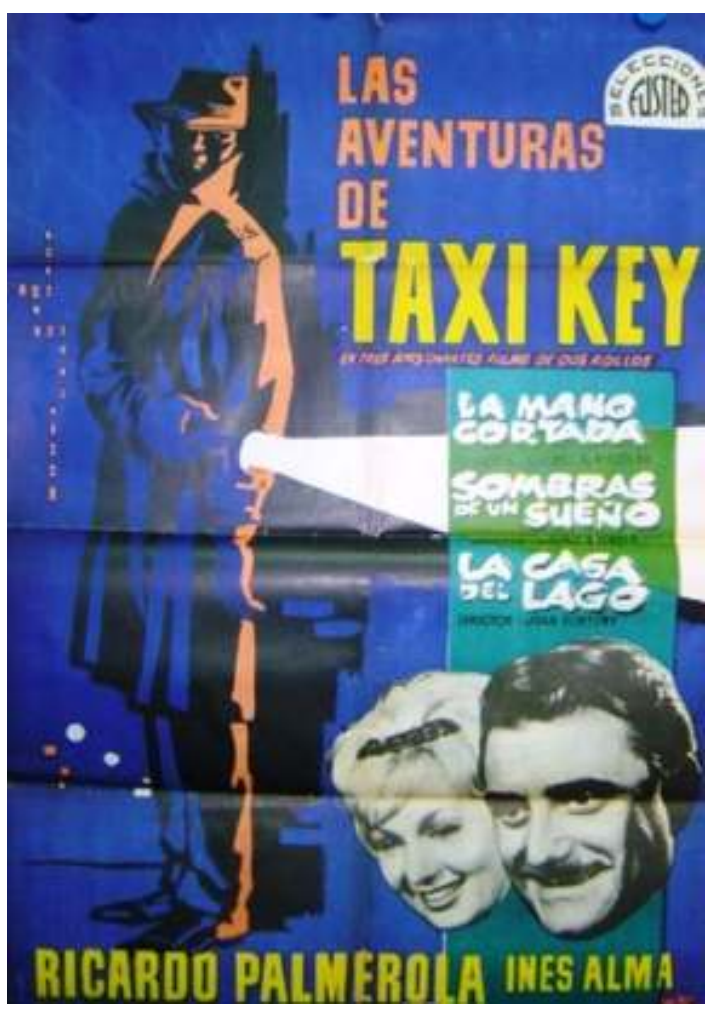

37

Si Taxi Key fue concebido para la televisión, no me cabe duda de que hubiese pasado a la historia como la mejor serie española. Pero en 1959 no estaba aún la televisión en España para proyectos de esa envergadura. Nacida a principios de la década, en 1951 comienzan las primeras pruebas, reducidas al ámbito de Madrid capital: dicen que 
cuando iban a hacer alguna emisión avisaban por teléfono a los escasos potentados que poseían un receptor.

En 1956 ya se comienza una emisión fija.

39 Ya en 1957 nace la primera serie de televisión, En casa de los Rodríguez, los que los americanos llaman una sitcom, que es una abreviatura de Situation Comedy (Comedia de situación), que generalmente narra peripecias familiares en un contexto de comedia; en este caso, de los Rodríguez, una típica familia española de clase media de la época. Ese tipo de series es de bajo presupuesto, solo hacen falta unos cuantos actores recitando unos diálogos supuestamente graciosos (en Norteamérica vienen acompañados con un fondo de risas para indicarle al telespectador cuando deben reírse) y un decorado representando un piso con unos cuantos muebles.

Y en 1959 se inicia un periodo de expansión a escala nacional, extendiéndose progresivamente la cobertura a todo el territorio nacional. Sin embargo, queda aún por vencer una gran dificultad: el receptor de televisión no se fabrica en España, es un producto de exportación de superlujo. A principios de la década de los 60 comienza la fabricación en España, con ayuda gubernamental para dar facilidades de compra y difundir el nuevo medio de comunicación. En la segunda mitad de la década la cobertura alcanza a toda España, si bien solo en los grandes núcleos de población, ya que en las zonas rurales sigue siendo algo casi mágico, de lo cual los que han oído hablar de la televisión lo comentan aureolándolo de leyenda.

41 Visto las cosas así, es fácil suponer que las grandes marcas patrocinadoras en el año 1959, en que se rodaron los tres episodios de Taxi Key, se decantarían por la radio; es un claro ejemplo de adelanto a la época, una década después no es de extrañar que hubiese alcanzado un gran éxito. 


\section{La novela}

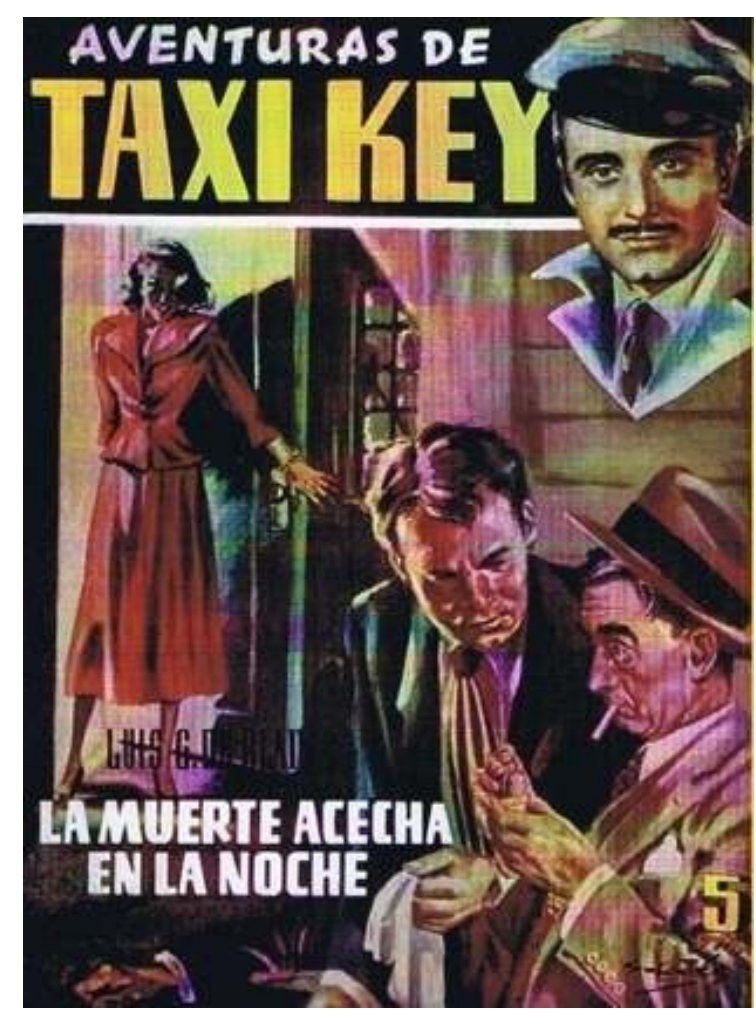

42 Aquí es más difícil señalar un motivo claro, pues peores colecciones hubo en aquel tiempo que alcanzaron mayor longevidad.

Cierto es que Luis Gossé es un narrador de recursos limitados, sus personajes son esquemáticos, no profundiza en los caracteres: en cambio hace una descripción bastante aceptable de ambientes, preferentemente de lugares cerrados, quizá por ser más proclives al crimen y el misterio. Quizá estas carencias narrativas devengan del hecho de haberse acostumbrado a escribir para la radio.

La novela tiene una buena presentación, una atractiva portadas e ilustraciones convincentes, aunque decir novela es exagerar: más bien un relato largo, ya que al final De Blain mete un relato corto con el consabido problema policíaco, restándole extensión a la ya de por si corta novela.

No sé si el número de ventas no cumplió las expectativas del editor o se De Blain estaba demasiado ocupado con la radio para seguir escribiendo (lo cual se contradice con el hecho de que al final de la novela se anunciaba la próxima con su título y sinopsis, lo cual indica que al menos ya tendría un borrador preparado): lo cierto es que no pasó del número 1. 


\section{Historieta}

\section{aventuras ot}

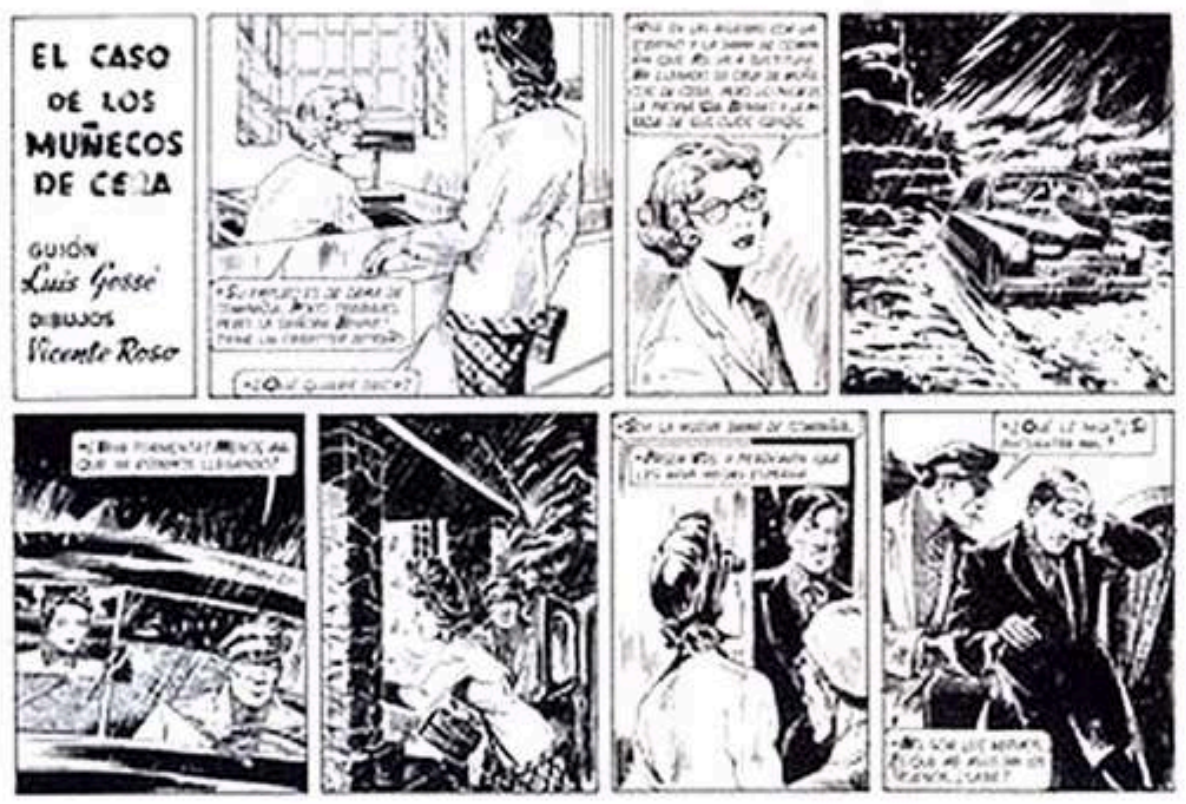

No tuvo una colección propia, sino que aparecía en historias de dos páginas en la revista El Coyote, de Ediciones Clíper.

La autoría gráfica es de un excelente dibujante, Vicente Roso, cuya labor se desarrolló principalmente en la revista para chicas Florita, de la misma casa editorial. El dibujo se ve perjudicado por la condensación de la historia, constreñido a unas viñetas minúsculas para encajar la historia en solo dos páginas.

48 Si a esto le sumamos que presenta de nuevo el consabido problema policiaco que debe resolver el lector, no es de extrañar que tampoco tuviese mucho éxito.

49 El personaje volvió a presentar sus problemas policiacos -premios incluidos- a comienzo de los años 80 en la revista Gimlet.

\section{La radio}

50 Aquí es donde el personaje tiene más éxito: pero, que yo sepa, la emisión no fue a escala nacional, circunscribiéndose su emisión a Cataluña.

\section{Conclusiones finales}

Decía al principio que al igual que El Coyote, Taxi Key apareció en todos los medios de comunicación. A diferencia de él, que tuvo duración en todos los medios, Taxi Key solo tuvo una presencia continuada en la radio. He tratado de argüir diversos razonamientos como posibles explicaciones de ello: pero la principal, es la enorme diferencia en la calidad literaria que existía entre uno y otro personaje. 


\section{RESÚMENES}

El artículo propone una aproximación a Taxi Key, una serie de ficción radiofónica que contó con una considerable audiencia en la década de los cincuenta. Tras presentar la figura de su creador, se analiza el papel de la radio en el contexto social de la época, la aportación del actor vocal que la protagonizó, además de las distintas adaptaciones de las que fue objeto.

\section{ÍNDICE}

Palabras claves: Taxi Key, Luis Gossé De Blain, radionovela, Ricardo Palmerola

\section{AUTOR}

\section{PABLO MÁRQUEZ}

Escritor

capitanrido413@gmail.com 